\title{
Green synthesis of carbon quantum dots from sumac: characterization and investigation with cyclic voltammetry technique
}

\author{
Mustafa ÇEŞME ${ }^{1, *(D)}$, Hasan ESKALEN ${ }^{2}$ \\ ${ }^{1}$ Kahramanmaras Sütçü Imam University, Faculty of Art and Sciences, Department of Chemistry, 46040, Kahramanmaras / Turkey. \\ ${ }^{2}$ Kahramanmaraş Sütçü Imam University, Vocational School of Health Services, Department of Opticianry, Kahramanmaraş / Turkey.
}

\begin{abstract}
Carbon dots, due to their minimal size, non-toxicity, simple, cheap and easy synthesis; Among the studies on nanostructured materials that have attracted attention in recent years; has become a popular study topic for researchers. In this study, for the first time, Sumac was used as a source of carbon, and carbon dots were obtained by using the hydrothermal synthesis method in a one-pot reaction at $175^{\circ} \mathrm{C}$ for 8 hours without using any chemical reagents. The characterizations of the obtained carbon dots were illuminated by various analytical instruments (High-Resolution Transmission Electron Microscope (HR-TEM), X-ray Diffractometer (XRD), Raman, Photoluminescence, Infrared, and Uv-vis spectrometer). According to the TEM results, the average diameter of carbon dots was found as $10.48 \mathrm{~nm}$. The maximum emission peak of the carbon dots was monitored at $428 \mathrm{~nm}$ when excited at 350 $\mathrm{nm}$. In the next step, the electrochemical properties of the carbon dots were examined by cyclic voltammetry technique. According to cyclic voltammetry results, the substance transport on the electrode surface by diffusion controlled.
\end{abstract}

\section{Article info}

History:

Received:12.01.2020

Accepted:12.06.2020

Keywords:

Sumac,

Carbon dots,

Photoluminescence,

Cyclic Voltammetry

\section{Introduction}

Sumac is the generic name of the Rhus genus belonging to the Anacardiaceae family [1]. It is a small tree that reaches $4 \mathrm{~m}$. height, and it is commonly seen in the Mediterranean areas and South-eastern Anatolian areas of Turkey [2]. The sumac has been used as traditional medicine and nutrient for centuries [3-6]. The extracts of sumac contain various biologically active components, including anthocyanins, malic, citric, and tartaric acids, and several kinds of phenolic substances [5, 7 , 8]. Moreover, the chemical composition of sumac has been investigated in terms of carbohydrate, protein, mineral, and vitamin content [4]. Nowadays, the treatment of some diseases with sumac and sumac related materials has been studied $[2,8]$. Therefore sumac plays a critical role in different research areas, and the increasing attention has been the focus on its and associated applications.

Carbon nanoparticles with a spherical shape, minimal diameter size, which chiefly includes oxygen, hydrogen, and other elements, are identified as carbon quantum dots (CQDs) and/or simple carbon dots (CDs)
[9]. The application areas of CDs have been increasing day by day. For instance, CDs are used in bio-imaging, optoelectronics, catalysis, and sensing applications $[10,11]$. Considering only applications in the sensing area, cation-anion, small and macro-molecule, cell and bacteria, test paper, hydrogel, and fingerprint sensing of CDs, which are separately significant fields in sensing, have been investigated by researchers [12]. The reason behind attracting the interest of CQDs is a carbon atom is an abundant element that implies cost efficiency and its biocompatibility because of nontoxic. Moreover, CQDs have unique structural and electronic properties such as good water solubility, tunable photoluminescence properties $[13,14]$. Hydrothermal synthesis is one of the most popular synthesis methods of carbon dots because of its simplicity and cost efficiency [15][16], and the characteristic of CDs partially depends on the used raw carbon sources [15]. Various carbon sources; banana juice [17], orange peel [18], cabbage [19], onion waste [20], walnut shell [21], and rosemary leaves [22] have been used to produce CDs.

In this study, we produced a rapid and straightforward synthesis of CDs using sumac as a carbon source 
without the requirement of any chemical reactant and agent. The electrochemical properties of the synthesized CQDs were explored. As far as we know, the presented work is the first experimental study about sumac derived carbon dots and also the investigation of electrochemical properties of the synthesized carbon quantum dots.

\section{Materials and Methods}

\subsection{Apparatus and reagents}

XRD pattern of the sample was measured with Philips $\mathrm{X}^{\prime}$ Pert PRO XRD with $\mathrm{Cu} \mathrm{K} \alpha$ radiation $(\lambda=0.154056$ $\mathrm{nm}$, set at $40 \mathrm{kV}$ and $30 \mathrm{~mA}$ ). The morphological properties of prepared CQDs were observed by using Transmission Electron Microscopy (JEOL JEM 2100, UHR). UV-vis absorption spectra and Photoluminescence (PL) spectrum were collected on Shimadzu-1800 UV-vis spectrometer and Varian Cary Eclipse spectrometer, respectively. Raman spectrum of synthesized CQDs was investigated with a portable Raman spectrometer (BWS465 B\&W Tek Inc.,) with a $302 \mathrm{~mW}$ diode laser at $785 \mathrm{~nm}$. Infrared spectroscopy
(FTIR) was carried out on a Perkin Elmer Spectrum 400 with a universal demountable cell mount for liquid samples. The $\mathrm{pH}$ meters Thermo Scientific A215 used for the $\mathrm{pH}$ measurements.

\subsection{Synthesis of the c-dots}

Sumac was chosen as a carbon source. The sumac sample was sourced from a local convenience store selling spice products, first washed several times with tap water and deionized water. $50 \mathrm{ml}$ Teflon-lined stainless steel autoclave was used for hydrothermal reaction, and synthesis parameters were set as $175{ }^{\circ} \mathrm{C}$ for $8 \mathrm{~h}$. After the end of the reaction time, the thermal autoclave was left to cool spontaneously at room temperature. The obtained brown-black solution mixture was filtered and subject to a centrifuge for 25 $\min$ at $14.000 \mathrm{rpm}$. The supernatant was refrigerated at $4{ }^{\circ} \mathrm{C}$ for experimentation and characterization processes that would be carried out in later stages. Typical colloidal solution of CDs contained 1 $\mathrm{mg} / 1 \mathrm{~mL}$. Figure 1 illustrates the synthesis method and the characterization of CDs.

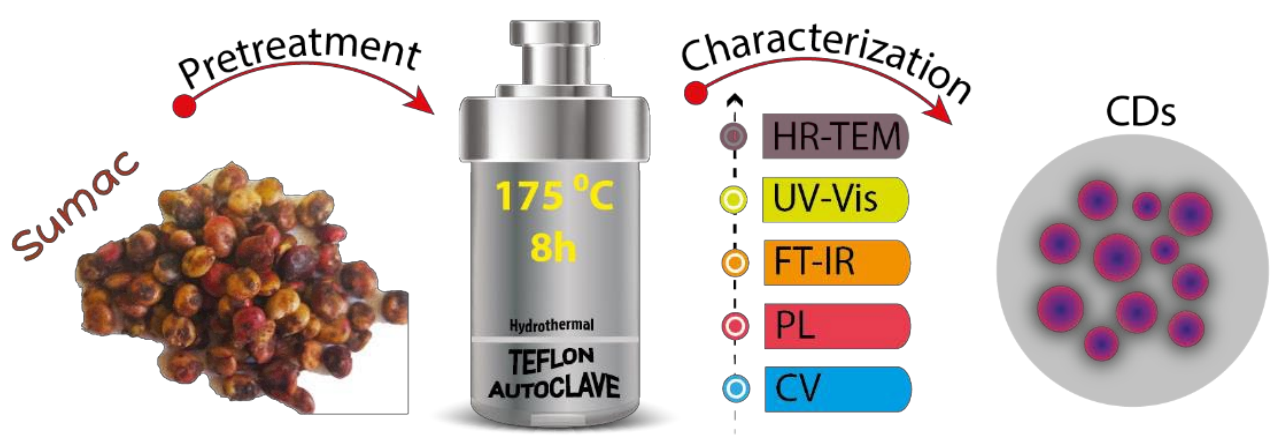

Figure 1. Schematic representation of CDs derived from sumac by hydrothermal method.

\subsection{Electrochemical procedures}

In electrochemical studies, cyclic voltammetry technique (CV), BAS $100 \mathrm{~W}$ electrochemical analyzer was utilized. In all experiments, glassy carbon electrodes were used as working electrodes. The platinum wire electrode as an auxiliary electrode and $\mathrm{Ag} / \mathrm{AgCl}$ electrode as a counter electrode were also utilized. An easy pretreatment was employed to the glassy carbon working electrode in order to create a repeatable electrode surface. Little quantity of aluminum oxide $\left(\mathrm{Al}_{2} \mathrm{O}_{3}\right)$ dust was positioned on a silky polishing cloth particularly made for this electrode and soaked with distilled water, and the electrode surface was polished in a circular motion. On account of confirming the best reproducibility, these pre-process were replicated in several numbers, and the optimum polishing count was determined. After the pretreatment, the polished electrode was washed with DI water and then dried with a soft cleaning paper and placed in to the glass cell. The platinum wire auxiliary electrode and the $\mathrm{Ag} / \mathrm{AgCl}$ reference electrode were removed from the experiment cell after each experiment, washed with distilled water, dried with drying paper, and placed in the experiment cell. All measurements were achieved at room temperature. 0.1 $\mathrm{M}$ phosphate buffer solution (PBS) at $\mathrm{pH} 7.4$ have been used as a supporting electrolyte. The amount of sample in the electrochemical cell was arranged by completing the final volume buffer solution to $10 \mathrm{~mL}$ to contain 1 $\mathrm{mL}$ of this colloid CDs solution. 


\section{Results and Discussion}

The morphological feature of synthesized CDs was examined by TEM observation. According to the TEM results given in Figure 2, the sumac-derived CDs were monodispersed and spherical. The average diameter of carbon dots was found as $10.48 \mathrm{~nm}$ from this figure. Moreover, narrow size diameter distribution CDs also clearly seen from this figure that implies the synthesized carbon dots had a very similar morphological structure.

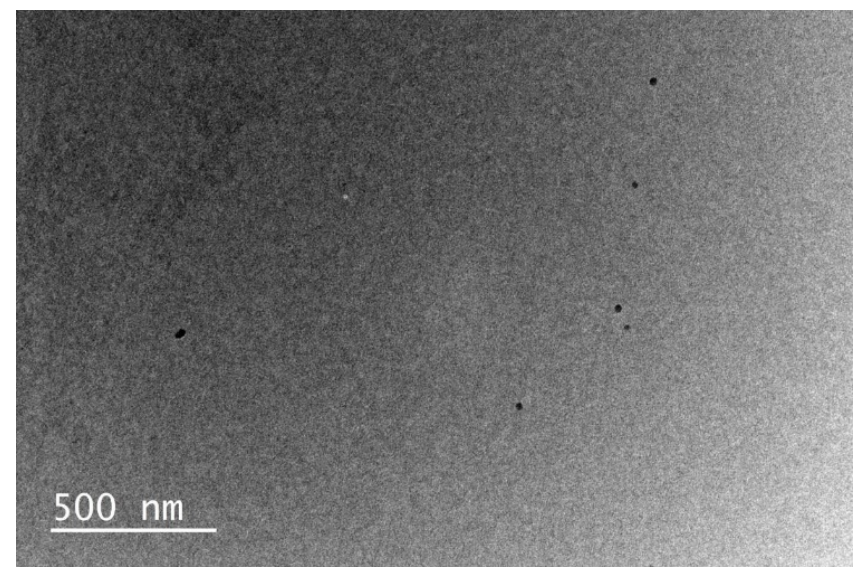

Figure 2. High-resolution transmission electron microscopy image of sumac derived CDs.

The crystalline structure of the CDs was examined with an XRD method. The XRD pattern of synthesized carbon dots gave a broad diffraction peak centered at $23.5^{\circ}$ and this wide diffraction peak of CDs demonstrated that the obtained CDs particles were mostly amorphous nature. Moreover, the peak also related to layer spacing of the (002) plane of the graphitic structure (Figure 3.) [9]. According to XRD results; XRD pattern is in harmony with the similar carbon dot studies $[23,24]$. When the Raman spectrum is examined (Figure.4), it has two distinct and sharp vibration peaks at $1343 \mathrm{~cm}^{-1}$ (the irregular network of $\mathrm{sp}^{2}$ carbon clusters) and $1538 \mathrm{~cm}^{-1}$ (graphitic (G) bands) [25].

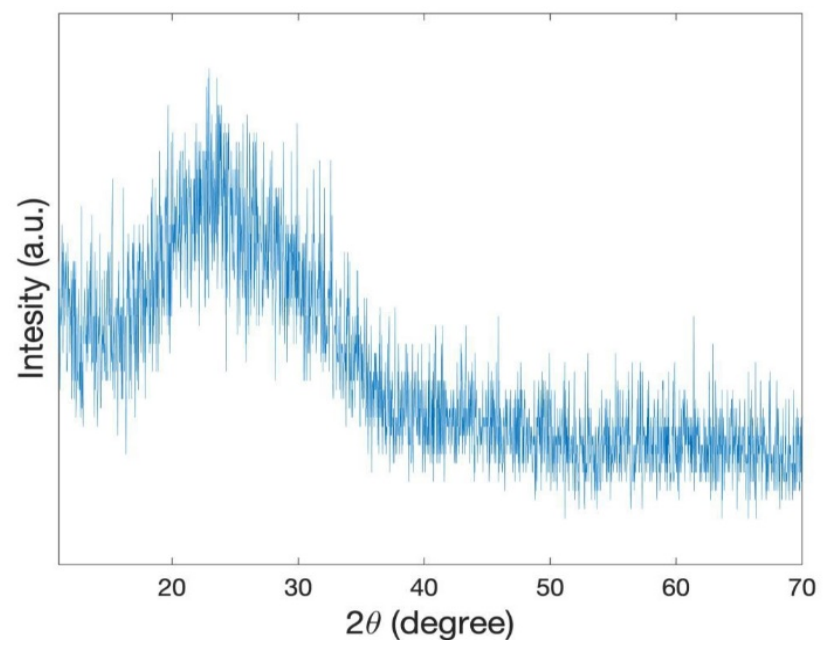

Figure 3. XRD diffraction pattern of the CDs.

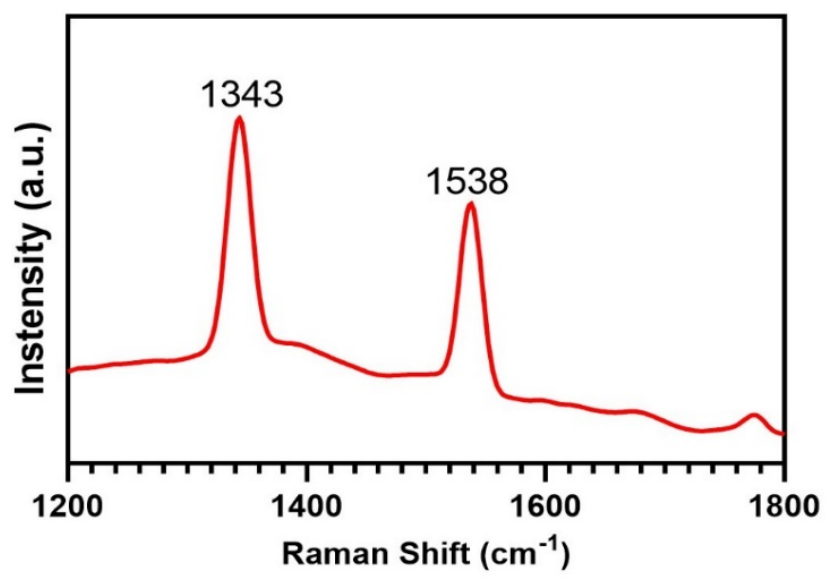

Figure 4. Raman Spectra of the CDs.

The optical properties of the carbon dots synthesized using the UV-vis spectrophotometer were examined, and the spectrum was given in Figure 5. Uv-vis spectra of CDs gave a broad absorption peak centered at about $278 \mathrm{~nm}$ that can be assigned to $\pi-\pi^{*}$ and $\mathrm{n}-\pi^{*}$ transition of conjugated $\mathrm{C}=\mathrm{O}$ or $\mathrm{C}=\mathrm{C}$ bond $[26,27]$. The photograph of Carbon dots under daylight and Uv light is exhibited in Figure 5 inset. The color of CDs is yellowish under daylight and bluish under the Uv light.

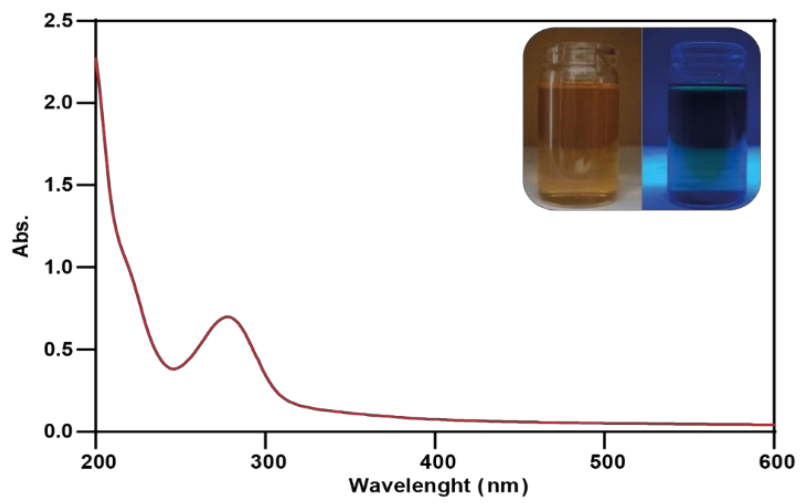

Figure 5. UV- Vis spectrum of CDs, the inset showing photographs of the prepared CDs solution under day light and Uv light. 
The excitation dependent photoluminescence emission spectra of carbon dots synthesized from sumac as a carbon source by hydrothermal methods were given in Figure 6. It was observed that with increasing excitation wavelength from 320 to 380 , the emission intensity of CDs was firstly increased and maximum emission value was obtained at excitation wavelength $350 \mathrm{~nm}$. At this point, the highest fluorescence intensity was found as 428. After than increasing excitation wavelengths results in a decrease in the emission peak of CDs. This result implies that changing excitation wavelength leads to tunable emission spectra, and it is might be the source from carbon core and supporting functional groups and uniform and non-uniform sized CDs [13].

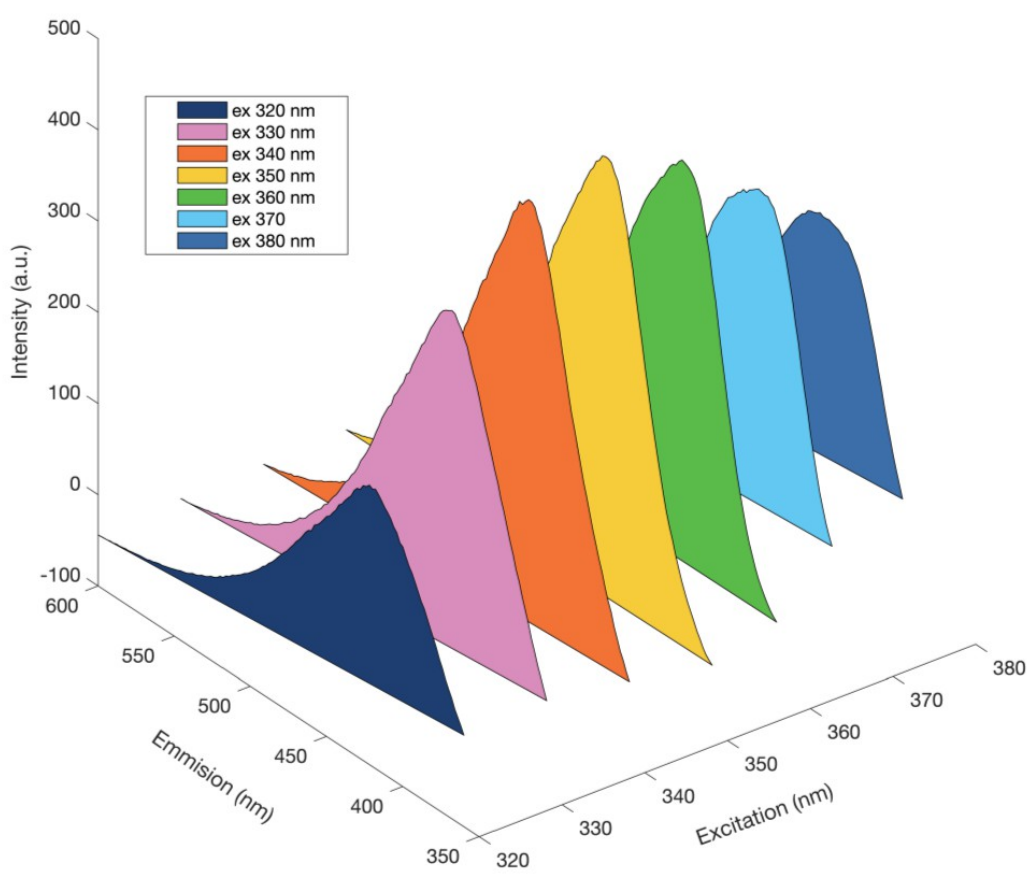

Figure 6. Excitation depended on PL spectra of synthesized CDs.

Infrared spectroscopy of the carbon dots proves the presence of prominent functional groups in the $\mathrm{C}$-dot structure. As shown in Figure 7, The FTIR spectrum of Sumac CDs characteristic absorption bands of shows $\mathrm{O}-\mathrm{H}$ vibration stretching and $\mathrm{C}-\mathrm{H}$ bending peaks at 3432 and $2626 \mathrm{~cm}^{-1}$, respectively. In $1639 \mathrm{~cm}^{-1}, \mathrm{C}=\mathrm{O}$ vibration stretching peaks are observed. These stretching peaks signal the existence of an $\mathrm{sp}^{2}$ hybridized honeycomb lattice of CDs [28].

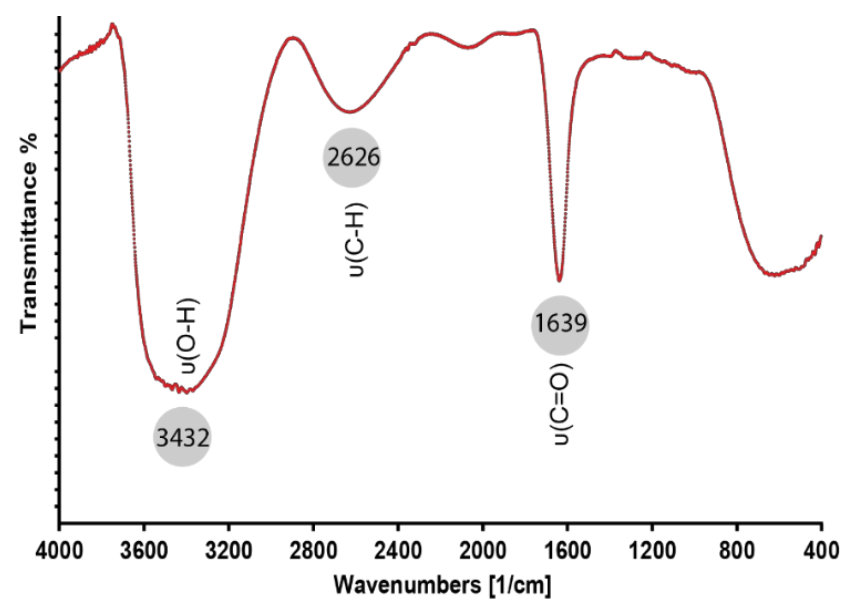

Figure 7. FTIR spectrum of CDs.
The electrochemical properties of sumac-derived CDs was examined by cyclic voltammetry technique after chemical, and structural characterization was performed through UV-vis, Raman, and photoluminescence spectroscopy. The CV technique has been worked cyclic between -2000 and $+2000 \mathrm{mV}$ for the potential sweep. Different scanning rates (10$1000 \mathrm{mV} / \mathrm{s}$ ) were used in order to understand and interpret the substance (mass) transport to the electrode surface. In scanning rate studies, measurements of up to $1000 \mathrm{mV} / \mathrm{s}$ have been taken, but anodic peak current has begun to disappear, especially at measurements with an increasing scanning rate higher than $350 \mathrm{mV} / \mathrm{s}$. Figure 8 reveals the usual cyclic voltammograms $(\mathrm{CV})$ curves in $0.1 \mathrm{M}$ PBS solution. As predicted, the CV graphs show the prominent redox peaks. As shown in the figure, peak currents increased gradually with increasing scanning rates. For measurements taken at $100 \mathrm{mV} / \mathrm{s}$; anodic peak current; $954 \mathrm{mV}$, cathodic peak current is around $-792 \mathrm{mV}$. 


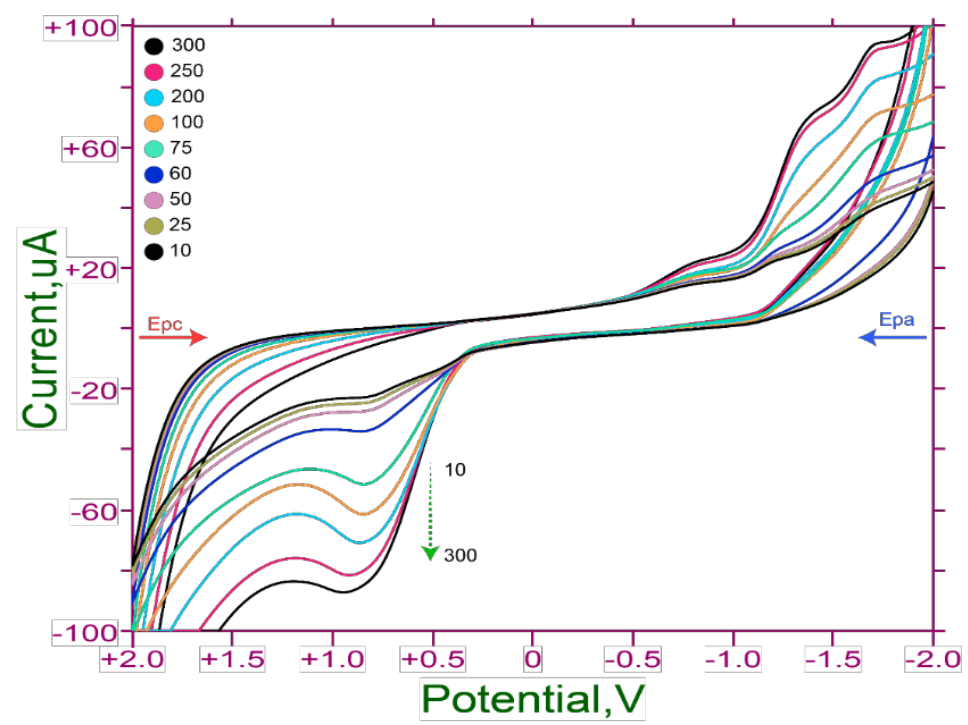

Figure 8. The scan rate (10-300 mV/s) effect on peak current of CDs in $0.1 \mathrm{M}$ PBS at $\mathrm{pH} 7.4$

Graphs describing the relationship between peak currents and scan rates shown in Figures 9 A and B were obtained from the voltammograms of Figure 8. The linearity of the peak current $\left(I_{\mathrm{p}}\right)$ depending on the square root of the scan rate was obtained by the electrode, demonstrating a diffusional behavior. These relations are stated as equations below.

$i_{\text {pa }}(\mu \mathrm{A})=4.759 v^{1 / 2}\left(\mathrm{mVs}^{-1}\right)+2.10, \mathrm{R}^{2}: 0.9939$

$i_{\mathrm{pc}}(\mu \mathrm{A})=0.847 v^{1 / 2}\left(\mathrm{mVs}^{-1}\right)+3.63, \mathrm{R}^{2}: 0.9971$

In similar scan rates; the effect of scan rates on peak current were also analyzed with a graph of the logarithm of peak current vs. scan rates logarithm that gives a straight line. These linear relations were acquired as follows (Figure 9);

$\log _{\text {ia }}(\mu \mathrm{A})=0.3786 \log v\left(\mathrm{mVs}^{-1}\right)+0.9731, \mathrm{R}^{2}: 0.9937$ $\log _{i c}(\mu \mathrm{A})=0.2422 \log v\left(\mathrm{mVs}^{-1}\right)+0.7366, \mathrm{R}^{2}: 0.9861$

According to these results, the relationship between the logarithm of the potential scanning rates and the logarithm of the peak current is between 0.37-0.24, and these values are near to 0.5 , which is the theoretical value, that indicates the substance transport on the electrode surface by diffusion (Figure 9 C, D). [29].
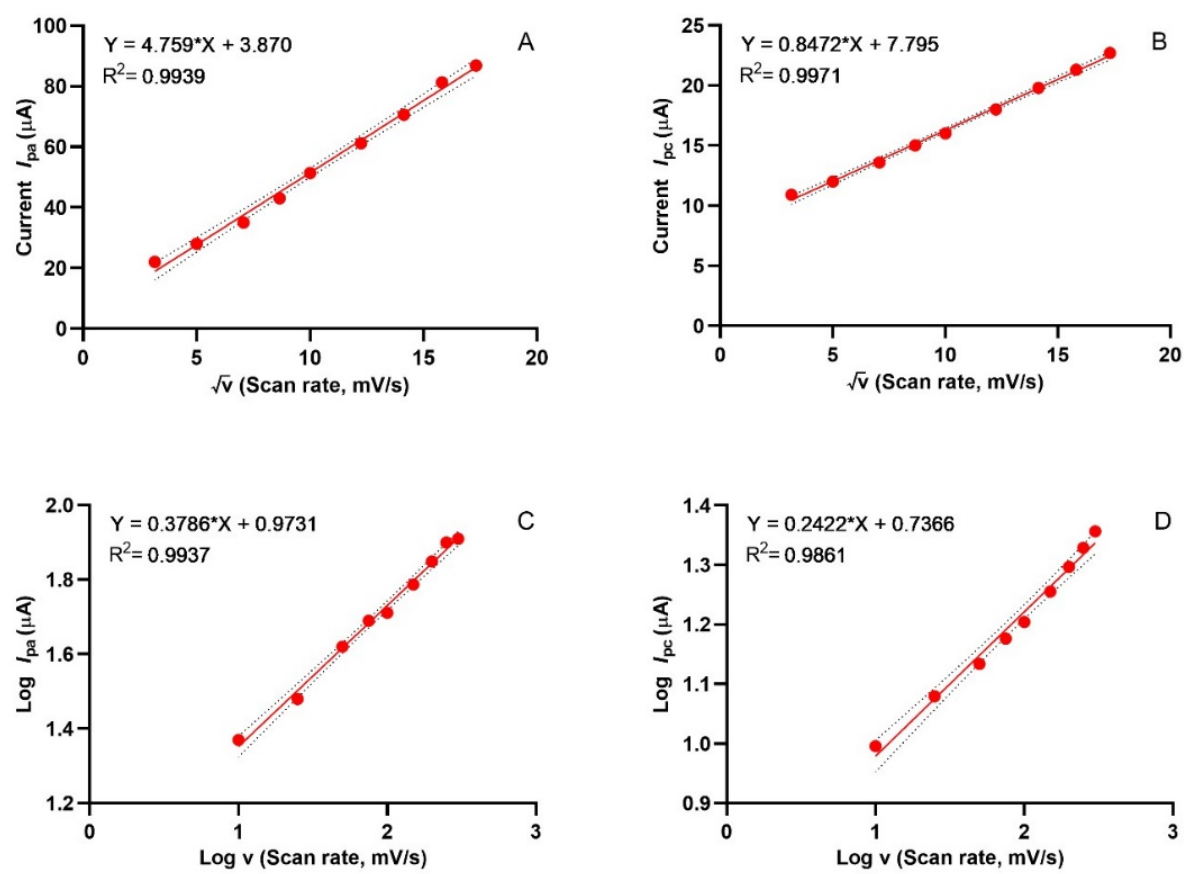

Figure 9. The linear relation between peak current and the square root of the scan rate; (A) anodic, cathodic (B), Plot of peak current vs. log of scan rate; (C) anodic, cathodic (D) 


\section{Conclusion}

In the present work, we efficiently synthesized CDs using a one-pot hydrothermal process, green and a simple approach, using sumac, which is a widely consumed spice. There is no study on sumac derivative carbon dots has been found in the conducted literature study until the we presented the article. The morphological features of the CDs were characterized by HR-TEM, and monodispersed spherical CDs with an average diameter of $10.48 \mathrm{~nm}$ was found. The crystalline structure of the carbon dots was investigated by XRD technique. Additionally, the optical properties of carbon dots were studied utilizing Uv-vis and PL spectrometry. The electrochemical properties of carbon dots results were obtained by cyclic voltammetry technique, and two characteristic peaks were determined from the measurements. Finally, since carbon dots contain both their properties before synthesis and after synthesizing, it has excellent potential to be used as an essential source in future studies, especially on bioimaging, biosensors, and drug release.

\section{Acknowledgment}

This work was financially supported by the Kahramanmaraş Sütçü İmam University Scientific Research Projects Coordination Unit (Project Number: 2019/5-21 M).

\section{Conflicts of interest}

The outhors state that did not have conflict of interests

\section{References}

[1] Caliskan G., Dirim SN., The effect of different drying processes and the amounts of maltodextrin addition on the powder properties of sumac extract powders, Powder Technol., 287 (2016) 308-314.

[2] Tohma H., Altay A., Köksal E. et al., Measurement of anticancer, antidiabetic and anticholinergic properties of sumac (Rhus coriaria): analysis of its phenolic compounds by LC-MS/MS, J Food Meas. Charact., 13 (2019) 1607-1619.

[3] Y1lmaz G., Eksi G., Demirci B. et al., Chemical Characterization of the Fatty Acid Compositions and Antmicrobial Activity of Sumac (Rhus Coriaria L.) Fruits, Growing Naturally in Turkey and Sold in Herbalist Markets, Ankara Univ.
Eczac. Fak. Derg., 44 (2020) 61-69.

[4] Wang S., Zhu F., Chemical composition and biological activity of staghorn sumac (Rhus typhina), Food Chem., 237 (2017) 431-443.

[5] Ghorbani P., Namvar F., Homayouni-Tabrizi M. et al., Apoptotic efficacy and antiproliferative potential of silver nanoparticles synthesised from aqueous extract of sumac (Rhus coriaria L.), IET nanobiotechnology, 12 (2018) 600-603.

[6] Sütyemez M., Güvenç G., Bükücü ŞB. et al., The Determination of Genetic Diversity among some Sumac (Rhus coriaria L.) Genotypes, ErwerbsObstbau., 61 (2019) 355-361.

[7] Shabestarian H, Homayouni-Tabrizi M., Soltani M. et al., Green synthesis of gold nanoparticles using sumac aqueous extract and their antioxidant activity, Mater Res., 20 (2017) 264-270.

[8] Wu Z., Zhang Y., Gong X. et al., The preventive effect of phenolic-rich extracts from Chinese sumac fruits against nonalcoholic fatty liver disease in rats induced by a high-fat diet, Food Funct., 11 (2020) 799-812.

[9] Zhang H., You J., Wang J. et al., Highly luminescent carbon dots as temperature sensors and "off-on" sensing of $\mathrm{Hg} 2+$ and biothiols, Dye Pigment, 173 (2020) 107950.

[10] Yuan F., Li S., Fan Z. et al., Shining carbon dots: Synthesis and biomedical and optoelectronic applications, Nano Today, 11 (2016) 565-586.

[11] Xu Q., Li W., Ding L. et al., Function-driven engineering of $1 \mathrm{D}$ carbon nanotubes and $0 \mathrm{D}$ carbon dots: Mechanism, properties and applications, Nanoscale, 11 (2019) 475-1504.

[12] Liu ML., Chen B Bin., Li CM. et al., Carbon dots: Synthesis, formation mechanism, fluorescence origin and sensing applications, Green Chem., 21 (2019) 449-471.

[13] Eskalen H., Uruş S., Cömertpay S. et al., Microwave-assisted ultra-fast synthesis of carbon quantum dots from linter: Fluorescence cancer imaging and human cell growth inhibition properties, Ind Crops Prod 147 (2020) 112209.

[14] Ghosal K., Ghosh A., Carbon dots: The next generation platform for biomedical applications, Mater Sci Eng C., 96 (2019) 887-903.

[15] Ding H., Du F., Liu P. et al., DNA-carbon dots function as fluorescent vehicles for drug delivery, ACS Appl Mater Interfaces, 7 (2015) 6889-6897. 
[16] Bandi R., Dadigala R., Gangapuram BR. et al., NDoped carbon dots with $\mathrm{pH}$-sensitive emission, and their application to simultaneous fluorometric determination of iron(III) and copper(II), Microchim Acta., 187 (2020) 1-10.

[17] De B., Karak N., A green and facile approach for the synthesis of water soluble fluorescent carbon dots from banana juice, RSC Adv., 3 (2013) 82868290 .

[18] Sahu S., Behera B., Maiti TK. et al., Simple onestep synthesis of highly luminescent carbon dots from orange juice: application as excellent bioimaging agents, Chem. Commun., 48 (2012) $8835-8837$.

[19] Alam A-M., Park B-Y., Ghouri ZK. et al., Synthesis of carbon quantum dots from cabbage with down-and up-conversion photoluminescence properties: excellent imaging agent for biomedical applications. Green Chem., 17 (2015) 3791-3797.

[20] Bandi R., Gangapuram BR., Dadigala R. et al., Facile and green synthesis of fluorescent carbon dots from onion waste and their potential applications as sensor and multicolour imaging agents, RSC Adv. 6 (2016) 28633-28639.

[21] Cheng C., Shi Y., Li M., et al., Carbon quantum dots from carbonized walnut shells: Structural evolution, fluorescence characteristics, and intracellular bioimaging, Mater. Sci. Eng. C. 79 (2017) 473-480.

[22] Rezaei B., Irannejad N., Ensafi AA., et al., The impressive effect of eco-friendly carbon dots on improving the performance of dye-sensitized solar cells, Sol. Energy, 182 (2019) 412-419.
[23] Arul V., Sethuraman MG., Hydrothermally Green Synthesized Nitrogen-Doped Carbon Dots from Phyllanthus emblica and Their Catalytic Ability in the Detoxification of Textile Effluents, $A C S$ Omega, 4 (2019) 3449-3457.

[24] Raji K., Ramanan V., Ramamurthy P., Facile and green synthesis of highly fluorescent nitrogendoped carbon dots from jackfruit seeds and its applications towards the fluorimetric detection of $\mathrm{Au} 3+$ ions in aqueous medium and in in vitro multicolor cell imaging, New J. Chem., 43 (2019) 11710-11719.

[25] Jayaweera S., Yin K., Hu X. et al., Fluorescent N/Al Co-Doped Carbon Dots from Cellulose Biomass for Sensitive Detection of Manganese (VII), J. Fluoresc., 29(6) (2010) 1291-1300.

[26] Pu ZF., Wen QL., Yang YJ. et al., Fluorescent carbon quantum dots synthesized using phenylalanine and citric acid for selective detection of Fe3+ ions, Spectrochim Acta - Part A Mol Biomol Spectrosc., 229 (2020) 117944.

[27] Sinha R., Bidkar AP., Rajasekhar R. et al., A facile synthesis of nontoxic luminescent carbon dots for detection of chromium and iron in real water sample and bio-imaging, Can. J. Chem. Eng., 98 (2020) 194-204.

[28] Atchudan R., Edison TNJI., Chakradhar D. et al., Facile green synthesis of nitrogen-doped carbon dots using Chionanthus retusus fruit extract and investigation of their suitability for metal ion sensing and biological applications, Sensors Actuators B. Chem., 246 (2017) 497-509.

[29] Wang J., Analytical Electrochemistry, New York: 3rd ed. John Wiley \& Sons, Inc., 2006. 